\title{
Analysis of risk factors of acute kidney injury in perioperative patients after lung transplantation
}

\author{
Xiaoshu Liu ${ }^{1 \#}$, Jing Zhang ${ }^{1 \#}$, Yang Yang ${ }^{1}$, Xiaobo Huang ${ }^{2}$, Xiaoqin Zhang ${ }^{2}$, Fuchun Zeng ${ }^{3}$, Gang Feng ${ }^{3}$, \\ Lu Guo ${ }^{1}$, Yang Xue \\ ${ }^{1}$ Department of Respiratory and Critical Care Medicine, Sichuan Provincial People's Hospital, University of Electronic Science and Technology \\ of China, Chengdu, China; ${ }^{2}$ Department of Critical Care Medicine, Sichuan Provincial People's Hospital, University of Electronic Science and \\ Technology of China, Chengdu, China; ${ }^{3}$ Department of Thoracic Surgery, Sichuan Provincial People's Hospital, University of Electronic Science \\ and Technology of China, Chengdu, China \\ Contributions: (I) Conception and design: X Liu; (II) Administrative support: L Guo, Y Yang, X Huang; (III) Provision of study materials or patients: \\ X Liu, X Zhang, F Zeng, G Feng, Y Xue; (IV) Collection and assembly of data: J Zhang; (V) Data analysis and interpretation: X Liu; (VI) Manuscript \\ writing: All authors; (VII) Final approval of manuscript: All authors. \\ \#These authors contributed equally to this work. \\ Correspondence to: Lu Guo. Department of Respiratory and Critical Care Medicine, Sichuan Provincial People's Hospital, University of Electronic \\ Science and Technology of China, Chengdu 610072, China. Email: 18981838226@163.com; Yang Xue. Department of Thoracic Surgery, Sichuan \\ Provincial People's Hospital, University of Electronic Science and Technology of China, Chengdu 610072, China. Email: 1659815999@qq.com.
}

Background: This study sought to examine the factors influencing acute kidney injury (AKI) in the perioperative period after lung transplantation (LT).

Methods: We collected and analyzed the clinical data of 25 patients, who were diagnosed with AKI in the perioperative period after LT at Sichuan Provincial People's Hospital from July 1, 2018 to June 30, 2020. Based on the clinical outcomes, the patients were divided into an AKI group and a non-AKI group. Differences between the two groups were compared, including differences in mechanical ventilation (MV) time and intensive care unit (ICU) stay time, the mode of transplantation, the total amount of dehydration in the first week after surgery, use of potential kidney damaging drugs, and whether extracorporeal membrane oxygenation (ECMO) was used.

Results: Nineteen patients $(76 \%)$ were diagnosed with AKI in the perioperative period after LT. There were no statistically significant differences between the two groups in terms of basic information, the mode of transplantation, the total amount of dehydration in the first week after surgery, the daily dose of tacrolimus, whether ganciclovir was used, whether voriconazole was used, whether ECMO was used, and mortality ( $>>0.05)$. However, the MV time and ICU stay time of the AKI group was longer than that of the non-AKI group ( $\mathrm{P}=0.006,0.011$, respectively). Analysis within the group shows there were no significant differences in terms of mortality, the MV time, and the ICU stay time between the AKI stage two group and the AKI stage three group (all $\mathrm{P}>0.05$ ). A multi-factor analysis was conducted in which AKI was the dependent variable, whether an amount of dehydration greater than 2,000 mL, a body mass index (BMI) greater than 18, and the use of ganciclovir and voriconazole had been examined as an independent variable; however, none of these were found to be risk factors associated with AKI.

Conclusions: The incidence of AKI in the perioperative period after LT is high. AKI in the perioperative period after LT prolonged patients' MV time and ICU stay time. In the perioperative management of LT, it is necessary to consider kidney protection to reduce the risk of AKI.

Keywords: Lung transplantation (LT); intraoperative complications; acute kidney injury (AKI); risk factors

$\wedge$ ORCID: 0000-0002-0375-7661. 
Submitted Jul 20, 2021. Accepted for publication Sep 09, 2021.

doi: 10.21037/apm-21-2094

View this article at: https://dx.doi.org/10.21037/apm-21-2094

\section{Introduction}

With the rapid development of solid organ transplantation, the use of lung transplantation (LT) technology as the only treatment for end-stage lung disease has become increasingly mature. LT improves the quality of life of recipients and prolongs survival significantly. The median survival time of lung transplant recipients is 6.5 years, which is still significantly lower than that of other solid organ transplants (1). Acute rejection and infection are important causes of perioperative death among lung transplant recipients (1). Additionally, renal dysfunction has become a major long-term complication after LT (2). The risk factors of acute kidney injury (AKI) during perioperative period of LT include: old age, complications, perioperative period, large circulation fluctuation, infection and the use of drugs for renal damage $(3,4)$. The occurrence of renal function impairment during the perioperative period of LT can increase recipients the incidence of chronic renal dysfunction and mortality (5), and unlike rejection and infection, renal function impairment is easily overlooked in complex clinical situations. Thus, further research needs to be conducted on the risk factors of AKI that occur during the perioperative period of LT to reduce and delay the occurrence and development of this major postoperative complication and prolong the survival time of lung transplant recipients. We present the following article in accordance with the STROBE reporting checklist (available at https://dx.doi. org/10.21037/apm-21-2094).

\section{Methods}

\section{Research object}

The medical records of 25 patients who underwent LT at Sichuan Provincial People's Hospital from July 1, 2018 to June 30, 2020 were collected.

\section{Inclusion criteria}

To be eligible to participate in this study, patients had to meet the following inclusion criteria: (I) be aged $\geq 18$ years; (II) be undergoing LT surgery; (III) meet the definition of AKI set out in the Kidney Disease: Improving Global
Outcomes (KDIGO) (6): show an increase of $0.3 \mathrm{mg} / \mathrm{dL}$ $(\geq 26.5 \mu \mathrm{mol} / \mathrm{L})$ of serum within 48 hours, or show an increase 1.5 times or more than that of the baseline value of serum creatinine within 7 days, or have a urine output $<0.5 \mathrm{~mL} /(\mathrm{kg} \cdot \mathrm{h}$ ) for 6 hours; (IV) develop AKI in the perioperative period of LT.

\section{Exclusion criteria}

Patients were excluded from the study if they met any of the following inclusion criteria: (I) died within 24 hours of the LT; (II) suffered from preoperative chronic kidney disease (CKD); (III) had no available life status data.

\section{Ethics}

All procedures performed in this study involving human participants were in accordance with the Declaration of Helsinki (as revised in 2013). The study was approved by the Sichuan Provincial People's Hospital's Medical Ethics Committee (No: 259 of 2019). Individual consent for this retrospective analysis was waived.

\section{Principles of treatment during the perioperative period of $L T$}

The main treatments received by patients during the perioperative period of LT include anti-rejection therapy, liquid volume management, infection prevention, rehabilitation, and nutritional therapy (7). To prevent primary graft dysfunction (PGD) and circulatory load after LT, a strict negative balance is implemented in the fluid management of lung transplant recipients to maintain transplant lung function.

\section{Observation indicators}

The patients were divided into two groups depending on whether AKI occurred during the perioperative period of LT. The method of transplantation, the total amount of dehydration in the first week after the operation, the daily dosage of tacrolimus, and whether ganciclovir, voriconazole, and extracorporeal membrane oxygenation (ECMO) were used during the perioperative period were included in the statistical analysis. 
Table 1 Comparison of the general conditions of the two groups with and without AKI during the perioperative period

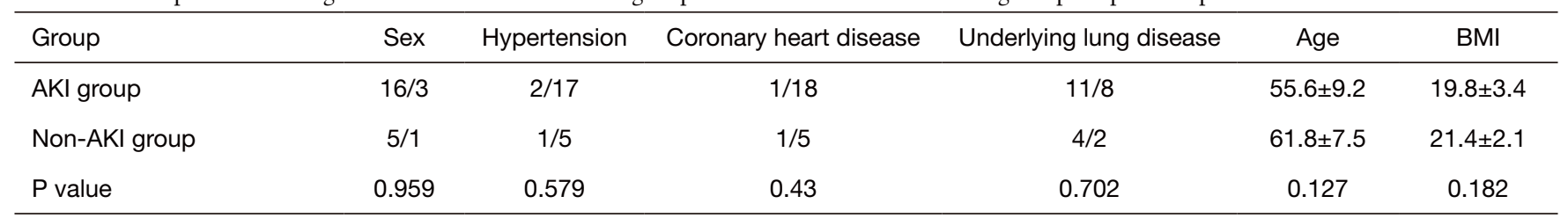

AKI, acute kidney injury; BMI, body mass index.

Table 2 Single-factor comparison of AKI between the two groups

\begin{tabular}{|c|c|c|c|c|c|c|}
\hline Group & $\begin{array}{c}\text { Transplantation } \\
\text { method }\end{array}$ & $\begin{array}{l}\text { Total amount of } \\
\text { dehydration in the } \\
\text { first week after } \\
\text { surgery }(\mathrm{mL})\end{array}$ & $\begin{array}{l}\text { Daily dosage of } \\
\text { tacrolimus }(\mathrm{g} / \mathrm{d})\end{array}$ & $\begin{array}{c}\text { Whether } \\
\text { ganciclovir used }\end{array}$ & $\begin{array}{c}\text { Whether } \\
\text { voriconazole used }\end{array}$ & $\begin{array}{l}\text { Whether } \\
\text { ECMO used }\end{array}$ \\
\hline $\mathrm{AKI}$ group & $9 / 10$ & $2,937.1 \pm 2,028.6$ & $4.2 \pm 1.0$ & $12 / 7$ & $6 / 13$ & $9 / 10$ \\
\hline Non-AKI group & $3 / 3$ & $1,912.8 \pm 669.9$ & $4.0 \pm 1.6$ & $3 / 3$ & $3 / 3$ & $3 / 3$ \\
\hline
\end{tabular}

$\mathrm{AKI}$, acute kidney injury; ECMO, extracorporeal membrane oxygenation.

\section{Statistical methods}

SPSS22.0 statistical software was used to process the data. Normally distributed measurement data is represented as $\bar{x} \pm \mathrm{s}$. The $t$-test was used for comparisons between the groups. The measurement data of skewed distribution is represented by the median (interquartile range) $[\mathrm{M}(\mathrm{QL}$, $\mathrm{QU})$ ], and the non-parametric rank-sum test was used. Count data are expressed as a percentage (\%), and the comparison of rates and categorical variables were tested using Fisher's exact probability method. A $\mathrm{P}<0.05$ was considered statistically significant.

\section{Results}

\section{Basic information}

Among the 25 lung transplant recipients, 19 patients developed AKI during the perioperative period. Thus, there was an incidence rate of $76 \%$. Among the 19 patients with AKI, 16 were male and 3 were female, and these

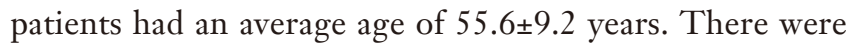
8 cases of pulmonary interstitial fibrosis and 11 cases of chronic obstructive pulmonary disease, and 3 cases of hypertension and 2 cases of coronary heart disease among them. The general information of the two groups was balanced, and the differences were not statistically significant (see Table 1).

\section{Univariate analysis of AKI in lung transplant recipients during the perioperative period}

The transplantation method, the total amount of dehydration in the first week after surgery, the daily dosage of tacrolimus, whether ganciclovir was used, whether voriconazole was used, whether ECMO was used during the perioperative period between the AKI group and the nonAKI group were compared. The results showed that the differences were not statistically significant (all $\mathrm{P}>0.05$; see Table 2).

\section{Single-factor comparison of clinical outcomes in the intensive care unit (ICU) of the two groups with or without AKI}

There was no statistically significant difference in the mortality rate between the AKI group and the non-AKI group. The mechanical ventilation (MV) time and ICU stay time of the AKI group was longer than that of the non-AKI group ( $\mathrm{P}=0.006,0.011$; see Table 3).

\section{Comparison of ICU clinical outcomes at different stages in the AKI group}

The lung transplant recipients who developed AKI were divided into AKI2 and AKI3 groups according to the AKI stages. There were no significant differences in the 
Table 3 Comparison of ICU clinical outcomes between the two groups

\begin{tabular}{lccc}
\hline Group & Case fatality rate & MV time $(\mathrm{h})$ & ICU stay time (days) \\
\hline AKI group & $5 / 14(66.7 \%)$ & $63.0(22.0,114.0)$ & $10(6.0,15.0)$ \\
Non-AKI group & $1 / 5(25.0 \%)$ & $15.0(8.0,28.0)$ & $4.0(2.0,9.0)$ \\
P value & 0.629 & 0.006 & 0.011 \\
\hline
\end{tabular}

ICU, intensive care unit; MV, mechanical ventilation; AKI, acute kidney injury.

Table 4 Comparison of ICU clinical outcomes at the different stages of AKI

\begin{tabular}{|c|c|c|c|c|c|}
\hline AKI stage & Case fatality rate & MV time $>48 \mathrm{~h}$ group & MV time $<48$ h group & ICU stay time $>1$ week & ICU stay time $<1$ week \\
\hline 2 stage & $1 / 5(20.0 \%)$ & 3 & 3 & 5 & 1 \\
\hline 3 stage & $4 / 9$ (44.4\%) & 8 & 5 & 8 & 5 \\
\hline$P$ value & 1.0 & 1.0 & & 0.605 & \\
\hline
\end{tabular}

ICU, intensive care unit; AKI, acute kidney injury; MV, mechanical ventilation.

Table 5 Logistic regression analysis of AKI in lung transplant recipients during the perioperative period

\begin{tabular}{lcccccc}
\hline Variables & $\begin{array}{c}\text { Regression } \\
\text { coefficients (B) }\end{array}$ & SE & $\begin{array}{c}\text { Wald test } \\
\text { statistics }\end{array}$ & P value & $\begin{array}{c}\text { OR value } \\
\begin{array}{c}95 \% \text { confidence } \\
\text { interval for OR value }\end{array}\end{array}$ \\
\hline $\begin{array}{l}\text { Transplantation method } \\
\text { Total amount of dehydration in the first }\end{array}$ & 1.137 & 1.589 & 0.512 & 0.474 & 3.118 & $0.138-70.251$ \\
week after surgery & -0.965 & 1.589 & 0.364 & 0.546 & 0.381 & $0.017-8.740$ \\
BMI & -1.825 & 1.993 & 0.838 & 0.36 & 0.161 & $0.003-8.017$ \\
Ganciclovir & 0.543 & 1.364 & 0.158 & 0.691 & 1.721 & $0.119-24.918$ \\
Voriconazole & 0.09 & 2.203 & 0.002 & 0.967 & 1.095 & $0.015-82.093$ \\
ECMO & -0.093 & 1.682 & 0.003 & 0.956 & 0.911 & $0.034-24.628$ \\
\hline
\end{tabular}

AKI, acute kidney injury; SE, standard error; OR, odds ratio; BMI, body mass index; ECMO, extracorporeal membrane oxygenation.

mortality rates, whether the MV time was greater than $48 \mathrm{~h}$, and whether the ICU stay was greater than 1 week between these two groups (see Table 4).

\section{Logistic regression analysis of risk factors of AKI in lung transplant recipients during the perioperative period}

The dependent variable was the presence or absence of AKI in the research subjects. A multivariate analysis was conducted of the following independent variables: the transplantation method, whether the amount of dehydration in the first week after the operation was greater than 2,000 $\mathrm{mL}$, whether the body mass index (BMI) was greater than 18 , whether ganciclovir was used, whether voriconazole was used, and whether ECMO was used. The results showed that none of these risk factors were related to the occurrence of AKI (see Table 5).

\section{Discussion}

As of June 2017 , a total of 64,803 adult lung transplants had been registered by the International Society for Heart and Lung Transplantation. In 2016, a total of 4,054 lung transplants were performed globally, which is double the number 10 years ago (1). According to the definition of KDIGO, the global incidence rate of AKI is $22-57 \%(8,9)$. The incidence of AKI after LT is between $50-70 \%$ (10), and AKI can easily develop into CKD, which is related to the long-term mortality rate after LT (11). In this study, we retrospectively analyzed the relevant data of $25 \mathrm{LT}$ cases at 
our center, and explored the risk factors of AKI during the perioperative period of LT.

The incidence of AKI during the perioperative period of LT at our hospital was $76 \%$, which is equivalent to the level reported in the literature (10). From a clinical perspective, the underlying diseases that affect renal function include hypertension, coronary heart disease, diabetes and so on, and possible influencing factors for the occurrence of AKI after LT include excessive dehydration, the occurrence of perioperative infection, the use of potential kidney damaging drugs, and ECMO interventions. PGD is the main factor affecting the early survival rate after LT. The main principle for managing PGD is the strict control of the negative fluid balance (12). If the diuretic effect is poor, continuous renal replacement therapy (CRRT) should be started actively. Excessive dehydration was not observed to be associated with the occurrence of AKI during the perioperative period of LT in this study; however, in absolute terms, the amount of dehydration in the AKI group was much higher than that of the non-AKI group, which suggests that excessive negative fluid balance may induce AKI. Thus, in preventing PGD, it is necessary to consider whether the perfusion of the kidney is sufficient, and patients' renal function and urine output should be closely monitored during the perioperative period of LT. If vasoconstrictor drugs are needed, nitroglycerin could be infused at the same time or a "kidney dose" of dopamine could be used to offset the contraction effect on the renal blood vessels. However, giving AKI patients excessive fluid load will greatly reduce the possibility of renal function recovery (13). Thus, for lung transplant recipients who have developed AKI, it is important to note that the total fluid volume can't easily be too high. If necessary, CRRT can be initiated. However, the optimal CRRT start time for patients with severe AKI needs to be further explored (14). Thus, the effects of the management of the fluid balance after LT on the occurrence and recovery of AKI and the survival of lung transplant recipients require further investigation. Infection and rejection are also life-threatening complications in the perioperative period of LT, and have a clear impact on renal function. Therefore, broad-spectrum antibiotics and rejection drugs are routinely used to prevent and treat these complications after LT (7). Some biomarkers, such as urine neurophil gelatinase associated lipocalin (NGAL) and cystatin $\mathrm{C}(\mathrm{CyC})$ can help pay attention to the occurrence and risk stratification of AKI after heart transplantation (15), but the role of AKI in the perioperative period of LT needs to be observed.

Our studies have shown that the duration of MV in AKI patients is longer than that in non-AKI patients. For LT recipients who happened AKI during the perioperative period, fluid retention increases their cardiopulmonary load and their dependence on the ventilator, which in turn increases their risk of infection. This also prolongs the MV time of LT recipients who develop AKI. Some intertwined pathological factors, such as lung ischemia-reperfusion injury and ventilator-related lung injury, are also associated with the occurrence of AKI (16). Conversely, AKI increases the risk of offline failure by disrupting the steady state of the acid-base and liquid balance (17). MV increases intrathoracic pressure, which leads to an increase in the demand for the fluid load, which in turn promotes the progress of AKI, forming a vicious cycle of lung and kidney injury, and continuing the impairment of organ function. Thus, longer time of MV can increase the mortality of lung transplant recipients who develop AKI. Due to the small number of patients included in this study, there is a lack of statistical support for the difference in the mortality rates between the AKI and non-AKI groups. However, the absolute value of the fatality rate $(66.7 \%)$ of the AKI group was higher than that of the non-AKI group (25.0\%), and the fatality rate of the AKI 3 group was higher than that of the AKI2 group, which suggests that the increase in the fatality rate of AKI after LT. We hope to confirm this strong correlation in future studies. Previous studies have also reported that the severity of AKI is a predictor of early recovery for lung transplant recipients (18). A longer duration of AKI is associated with a worse clinical prognosis, which is similar to the risk that AKI patients face after other surgical procedures. In addition, compared to patients with persistent AKI, patients with transient renal function abnormalities after LT have a significantly higher survival rate (4).

In previous studies, independent risk factors related to the occurrence of AKI during the perioperative period of LT have included a higher BMI, the application of cyclosporine, and a longer MV time (4). It has also been reported that viral infection after transplantation may lead to impaired renal function (19). As the BMI of the lung transplant recipients selected at our hospital was generally balanced, it was difficult to distinguish between BMI levels statistically. The main immunosuppressive use after surgery was tacrolimus. According to each patient's condition, voriconazole antifungal, or ganciclovir antiviral was selected as appropriate. The current study did not find that the use of tacrolimus, voriconazole, ganciclovir, or ECMO were associated with the occurrence of AKI. Notably, it has been 
observed in clinical management that the effects of certain drugs on renal function is dose-dependent; however, as the current statistical data were insufficient, it was difficult to draw meaningful conclusions. Research has reported (20) that the use of ulinastatin and calcium blockers in the perioperative period of kidney transplantation can enhance the function of the transplanted kidney and prevent the renal toxicity of cyclosporine, but the renal protection in the perioperative period of LT is not yet clear.

In summary, the high incidence of AKI during the perioperative period of LT requires attention. In the perioperative management of LT, it is necessary to carefully grasp the dynamic balance of fluid, use drugs with little damage on the kidney, and prevent and control infections to reduce the risk of AKI. Once AKI occurs, comprehensive measures should be used to promote the recovery of renal function as much as possible to reduce the effects of AKI on the perioperative management of lung transplant recipients, reduce the possibility of CKD developing, and extend the survival time of lung transplant recipients as much as possible. In view of the mechanism, biomarkers, and comprehensive management of AKI in the perioperative period of lung transplant recipients, high-quality random control trials at multi-centers need to be conducted to generate evidence-based hypotheses.

\section{Acknowledgments}

Funding: Scientific Research Project of Sichuan Provincial Health Commission (Popular Application Project, 19PJ129).

\section{Footnote}

Reporting Checklist: The authors have completed the STROBE reporting checklist. Available at https://dx.doi. org/10.21037/apm-21-2094

Data Sharing Statement: Available at https://dx.doi. org/10.21037/apm-21-2094

Conflicts of Interest: All authors have completed the ICMJE uniform disclosure form (available at https://dx.doi. org/10.21037/apm-21-2094). Dr. XL reported that this work had received funding support from Scientific Research Project of Sichuan Provincial Health Commission (Popular Application Project, 19PJ129). The other authors have no conflicts of interest to declare.
Ethical Statement: The authors are accountable for all aspects of the work in ensuring that questions related to the accuracy or integrity of any part of the work are appropriately investigated and resolved. All procedures performed in this study involving human participants were in accordance with the Declaration of Helsinki (as revised in 2013). The study was approved by the Sichuan Provincial People's Hospital's Medical Ethics Committee (No: 259 of 2019). Individual consent for this retrospective analysis was waived.

Open Access Statement: This is an Open Access article distributed in accordance with the Creative Commons Attribution-NonCommercial-NoDerivs 4.0 International License (CC BY-NC-ND 4.0), which permits the noncommercial replication and distribution of the article with the strict proviso that no changes or edits are made and the original work is properly cited (including links to both the formal publication through the relevant DOI and the license). See: https://creativecommons.org/licenses/by-nc-nd/4.0/.

\section{References}

1. Chambers DC, Cherikh WS, Goldfarb SB, et al. The International Thoracic Organ Transplant Registry of the International Society for Heart and Lung Transplantation: thirty-fifth adult lung and heart-lung transplant report-2018; focus theme: multiorgan transplantation. J Heart Lung Transplant 2018;37:1169-83.

2. Wehbe E, Duncan AE, Dar G, et al. Recovery from $\mathrm{AKI}$ and short- and long-term outcomes after lung transplantation. Clin J Am Soc Nephrol 2013;8:19-25.

3. Siew ED, Davenport A. The growth of acute kidney injury: a rising tide or just closer attention to detail? Kidney Int 2015;87:46-61.

4. Fidalgo P, Ahmed M, Meyer SR, et al. Association between transient acute kidney injury and morbidity and mortality after lung transplantation: a retrospective cohort study. J Crit Care 2014;29:1028-34.

5. Wehbe E, Brock R, Budev M, et al. Short-term and long-term outcomes of acute kidney injury after lung transplantation. J Heart Lung Transplant 2012;31:244-51.

6. Khwaja A. KDIGO clinical practice guidelines for acute kidney injury. Nephron Clin Pract 2012;120:c179-84.

7. Zhang XQ, Pan LG, Huang XB. Experience of management to patients with lung transplantation in intensive care unit. China Modern Doctor 2016;54:158-60. 
8. Susantitaphong P, Cruz DN, Cerda J, et al. World incidence of AKI: a meta-analysis. Clin J Am Soc Nephrol 2013;8:1482-93. Erratum in: Clin J Am Soc Nephrol 2014;9:1148.

9. Hoste EA, Bagshaw SM, Bellomo R, et al. Epidemiology of acute kidney injury in critically ill patients: the multinational AKI-EPI study. Intensive Care Med 2015;41:1411-23.

10. Arnaoutakis GJ, George TJ, Robinson CW, et al. Severe acute kidney injury according to the RIFLE (risk, injury, failure, loss, end stage) criteria affects mortality in lung transplantation. J Heart Lung Transplant 2011;30:1161-8.

11. Paradela de la Morena M, De La Torre Bravos M, Prado $\mathrm{RF}$, et al. Chronic kidney disease after lung transplantation: incidence, risk factors, and treatment. Transplant Proc 2010;42:3217-9.

12. Lightle W, Daoud D, Loor G. Breathing lung transplantation with the Organ Care System (OCS) Lung: lessons learned and future implications. J Thorac Dis 2019;11:S1755-60.

13. Bouchard J, Soroko SB, Chertow GM, et al. Fluid accumulation, survival and recovery of kidney function in critically ill patients with acute kidney injury. Kidney Int 2009;76:422-7.

Cite this article as: Liu X, Zhang J, Yang Y, Huang X, Zhang X, Zeng F, Feng G, Guo L, Xue Y. Analysis of risk factors of acute kidney injury in perioperative patients after lung transplantation. Ann Palliat Med 2021;10(9):9841-9847. doi: 10.21037/apm-212094
14. Ren A, Li Z, Zhang X, et al. Optimal timing of initiating CRRT in patients with acute kidney injury after liver transplantation. Ann Transl Med 2020;8:1361.

15. Hošková L, Franekova J, Málek I, et al. Comparison of cystatin $\mathrm{C}$ and NGAL in early diagnosis of acute kidney injury after heart transplantation. Ann Transplant 2016;21:329-35.

16. Imai Y, Parodo J, Kajikawa O, et al. Injurious mechanical ventilation and end-organ epithelial cell apoptosis and organ dysfunction in an experimental model of acute respiratory distress syndrome. JAMA 2003;289:2104-12.

17. Koyner JL, Murray PT. Mechanical ventilation and the kidney. Blood Purif 2010;29:52-68.

18. Devarajan P. Update on mechanisms of ischemic acute kidney injury. J Am Soc Nephrol 2006;17:1503-20.

19. Barten MJ, Zuckermann A. BK virus: a cause for concern in thoracic transplantation? Ann Transplant 2018;23:310-21.

20. Chen $\mathrm{Y}, \mathrm{Mu} \mathrm{S}$, Wang J, et al. Chronic severe hepatitis and preoperative creatinine are independent risk factors for acute kidney injury after liver transplantation. Ann Transl Med 2020;8:1663.

(English Language Editor: L. Huleatt) 